\title{
The Artistic Multidimensional Performance of Red and Green Porcelain in Jin Dynasty
}

\author{
Shandan Ms. \\ Jingdezhen Ceramic Institute \\ Jingdezhen, China
}

\author{
Xiaosong Zou* \\ Jingdezhen Ceramic Institute \\ Jingdezhen, China \\ *Corresponding Author
}

\begin{abstract}
Red and green porcelain is a glazed painted porcelain created in Cizhou kiln during the middle and late Jin Dynasty. It is a kind of multi-color porcelain which applies paintings with red, green and yellow colors on the already finished white porcelain, and then applies the second high temperature bake in kiln. The red and green porcelains of Jin Dynasty embody the extraordinary decorative arts and cultural implications with brilliant colors, vivid shapes and smooth brushwork, which also occupy an important position in the history of Chinese porcelain. This paper attempts to explain the main reasons for its outstanding achievements by analyzing the influence of various art forms such as sculpture, painting and literature on the Jin Dynasty red and green porcelain.
\end{abstract}

Keywords-Jin Dynasty; red and green color; art; multidimension

\section{INTRODUCTION}

The red and green porcelain in Jin Dynasty is an outstanding contribution of Cizhou Kiln and the research on the red and green porcelain in Jin Dynasty has always been valued by scholars. Since the 1920 s, scholars have been studying and discussing it. Due to the lack of understanding of the ceramics in Jin Dynasty, early scholars named the red and green porcelain as Song Sancai or Song Jiacai. With the accumulation of archaeological data and the deepening of research, in the 1990s, the academic circles infer that the creation year of red and green porcelain is Jin Dynasty. Since then, the concept of the red and green porcelain in Jin Dynasty has gradually entered people's field of vision. According to the existing physical data and research results, the red and green color porcelains in Jin Dynasty showed outstanding achievements in decorative arts in the initial stage and reached a peak in the Zhangzong period. So, how was the art of the red and green colorful porcelain in Jin Dynasty formed? How does it interact with other plastic arts in the same period? What is the main reason for its outstanding achievements? This paper focuses on the above-mentioned problems, and analyzes and discusses the influence of sculpture, painting, literature and other art on the red and green porcelain.

\section{THE SCULPTURE LANGUAGE OF RED AND GREEN PORCELAIN IN THE JIN DYNASTY}

China's sculpture art has a very long history. In the Neolithic Age, there have been shaped ceramic sculptures, such as the statue of the "goddess" of the pottery sculpture discovered at the Niuheliang site of Hongshan Culture, which is the earliest figure statue discovered so far in China. After entering the civilized society, the types and materials of sculptures have become more and more abundant, the technology also has been continuously improved. The Tang and Song Dynasties were the mature period of the development of Chinese sculpture art, especially the stone carvings, pottery figurines and decorative sculptures of the Tang Dynasty, which occupied a very important position in the history of Chinese sculpture art.

The Jin Dynasty is a dynasty established by the Nuzhen Nationality, which is an ethnic minorities of northern China. The Jin people inherited the outstanding sculpture art traditions of Tang and Song Dynasties while incorporating the unique genes of the northern grassland people, thus achieved remarkable achievements in stone carving, wood carving, jade carving, brick carving, gold and silver, etc. The highly developed sculpture art also has a profound impact on the creation of Red and green porcelain, which is mainly reflected in the following aspects:

First of all, in the production process, the Red and green porcelain borrows the two techniques of sculpture art, circular engravure and relief. Most of the Red and green porcelain products adopt the method of molding, that is, first carved the mother mold, then rolling over to make the grinding tool, and finally the porcelain carcass is molded separately and combined together as one piece. ${ }^{1}$ This is very different from the molding method of sculpture art. However, the Red and green porcelain creates a circular engravure artistic effect of multi-dimensional and three-dimensional appreciation by filling the characters' headwear, costumes, and patterns with colored glaze on the semi-finished porcelain image. The Jin Dynasty Red and Green porcelain "Children Chasing Birds" collected in the Wangye Museum in Shenzhen is the most representative of the art of circular engravure art. Through the various methods of molding, painting, and bonding, the work expresses the combination of the boy, rockery, and sparrow; it has a certain appreciation from every angle. (See "Fig. 1") The art of red and green porcelain also uses more relief art techniques. The statues of $\mathrm{Hu}$ people collected in the Hongxi

Ma Xiaoqing. Analysis of the decoration technique of red and green color in Cizhou kiln [A]. The symposium of the Red and Green Porcelain in Shenzhen Museum [C] Cultural Relics Publishing Company 2011: 215. 
Art Museum in Taiwan has processed with relief techniques on the accessories such as hat and belt, which make the image vivid and three-dimensional. (See "Fig. 2") The Red and green porcelain of snake and scorpion fight which collected in Shenzhen Wangye Museum, it adhere the shaped sneak and scorpion on the rockery to create a semi-stereo bas-relief artistic effect, so that the wrestling scene of two reptiles are vivid and natural. (See "Fig. 3")

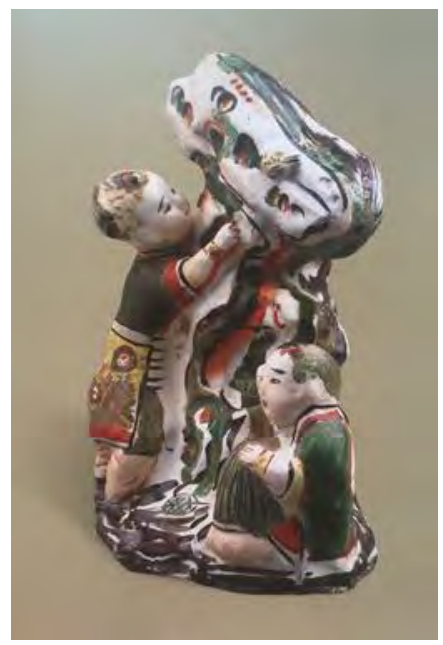

Fig. 1. The red and green porcelain of children chasing bird.

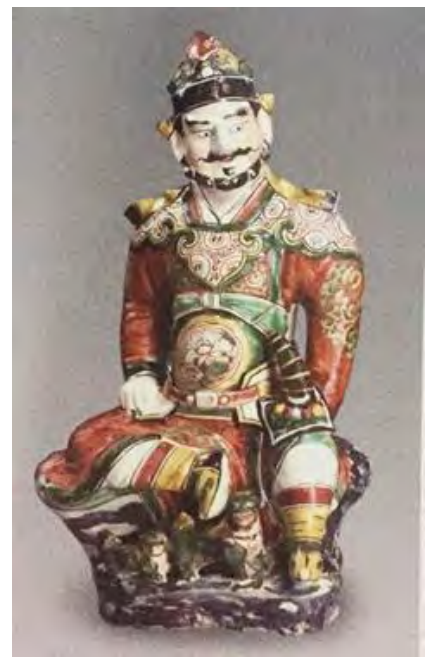

Fig. 2. The red and green porcelain of Hu people's image.

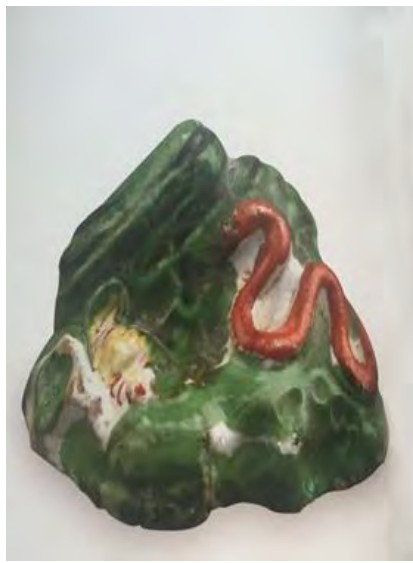

Fig. 3. The red and green porcelain of sneak and scorpion fighting against each other.

Secondly, in terms of artistic style, the Jin Dynasty red and green porcelain also drew nutrients from sculptures such as stone carvings, clay sculptures and wood carvings. In 1972, Jin Dynasty Red and Green Buddhist statues were unearthed in the Fengfeng mining area of Handan, Hebei. Among them, the statues of Sakyamuni, Manjusri and Samantabhadra were particularly eye-catching, relevant scholars called them "The Three Sages of Huayan". The concept of "The Three Sages of Huayan" is a theory formed in the Tang Dynasty. The sacred four ancestors of Huayan made it clear in "Three Sages Enter the Door of the Temple" that "The Three sages are the Sakyamuni, Manjusri and Samantabhadra". ${ }^{2}$ Due to the spread of Huayan Thought, a large number of works with the theme of "The Three Sages of Huayan" appeared in the art of stone sculpture, stone carving and bronze carving in Tang, Song and Liao Dynasty. Jin Dynasty inherited the legacy of the previous generation, still focus on the theory of harmony with Huayan. Typical representatives of the Jin Dynasty Huayan statue include the Manjusr Hall of Fo Guang Temple on Wutai Mountain in Shanxi Province, the statue of the Tibetan Buddhist Hall in Huayan Temple of Datong.

There are many similarities between the statues of "The Three Sages of Huayan" and the clay Buddha statues of the temples in Jin Dynasty. Take the Manjusri Bodhisattva as an example, the Manjushri and the Red and green Manjusri Bodhisattva in South Temple of Wutai Mountain all wear red and green corollas, vestment, sitting on the lotus pedestal of the lion's back, the lion is basically glaring angrily and open their mouth, the color of the head of the lion is mainly green. The difference is that the shape of the red and green Manjushri is simpler and overall, and many complicated details are saved. The lion-controlling person is not the "Kunlun Black Slave" in clay sculpture, but is an image of the person from Central Plains who has black hair and white skin. (See "Fig. 4", "Fig. 5") Obviously, the red and green Manjushri is more secular than the clay sculpture Manjusri. In addition to the influence of materials and molding processes, this change is also closely

2 Huang Yangxing. Solemn vivacity - Green color statue and the Buddhist beliefs of Jin Dynasty [A]. Shenzhen Museum Editor. Proceedings of the Chinese Red and Green Porcelain Symposium [C] Beijing: Cultural Relics Publishing Company.2011: 160. 
related to the aesthetics of the times and the changes of Buddhist culture.

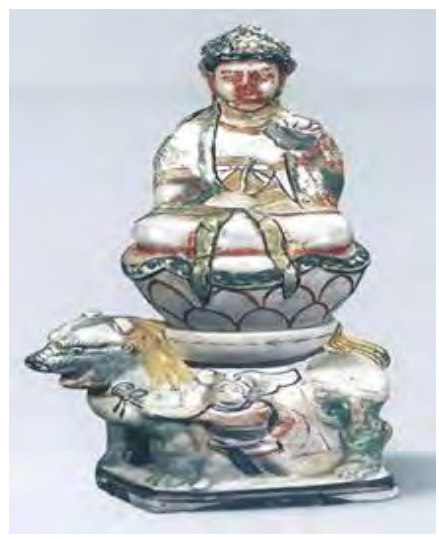

Fig. 4. The red and green porcelain of Manjusri Status.

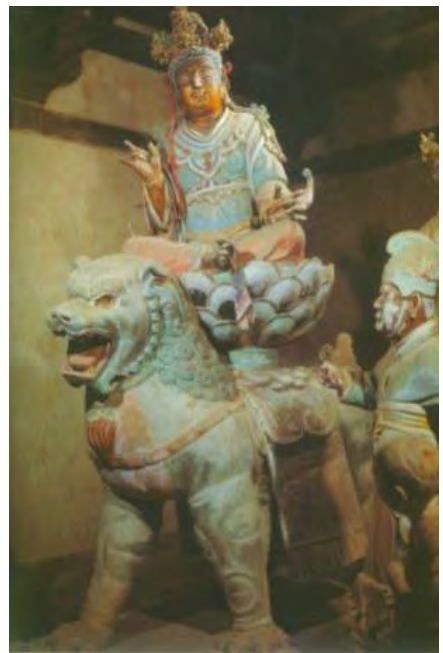

Fig. 5. Clay sculpture of Manjusri Status on the Wutai Mountains.

In addition to "The Three Sages of Huayan", the red and green color "Kwan-yin" statue is also a classic in the art of red and green porcelain, and its shape also reflects the close relationship with the sculpture art such as stone carving and wood carving since the Tang and Five Dynasties. Jin Dynasty Kwan-yin sculpture of Red and green porcelain collected in The Tianjin Museum wears a crown, has facial fullness, wear a necklace of jade and pearls, her left hand supports the ground, right hand on her knees, her left foot hangs down, steps on the lotus platform, and her right leg bent upward, the shape is extremely beautiful and vivid. This statue is very similar to the stone-carved Kwan-yin statues in Huangtong and Zhenyuan period of Jin Dynasty located in the second cave of Shihong Temple in Fuxian County, Shaanxi Province. It also has similarities with the Jin Dynasty woodcarving Kwan-yin sculpture collected by the American Nelson Museum of Art. (See "Fig. 6", "Fig. 7") In fact, the similarly shaped Kwan-yin sculpture has already appeared since the Five Dynasties period. The bronze statue of Kwan-yin from the Five Dynasties which collected in the National Museum wears a crown, has facial fullness, wear a necklace of jade and pearls, her left hand supports the ground, right hand on her knees, her left foot hangs down, steps on the lotus platform, and her right leg bent upward, the shape is beautiful and natural, the posture is quiet and serene, the left front is placed with a water bottle, and behind the statue placed with around-shaped backlight that symbolizes the full moon. (See "Fig. 8") Although the shape of Kwan-yin has changed somewhat from the Five Dynasties to Jin Dynasty, its basic sitting posture, which make the best expression of intrinsic philosophy of Kwan-yin has not changed. The Cizhou kiln artisans in Jin Dynasty are innovating at the same time by drawing on various sculpture art styles, thus producing a unique style of Kwan-yin sculpture of red and green porcelain.

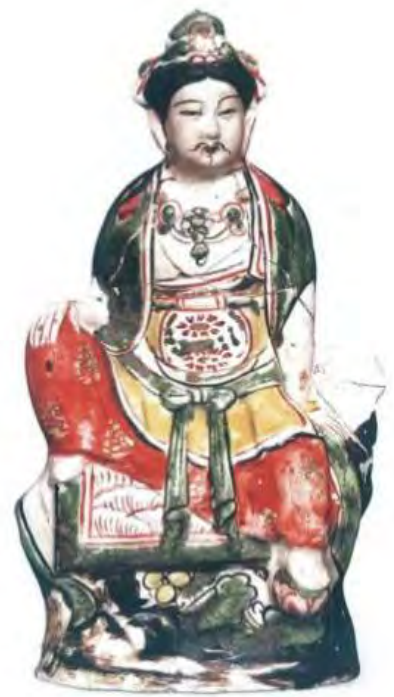

Fig. 6. The red and green porcelain of Kwan-yin Sculpture.

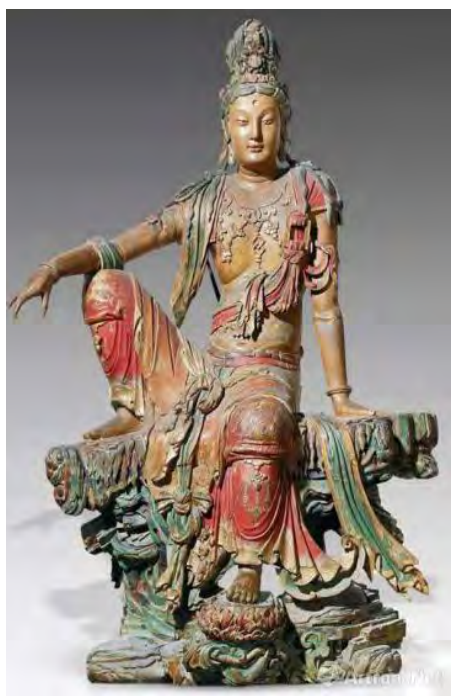

Fig. 7. Wood carving of Shui Yue Kwan-yin (Jin Dyansty). 


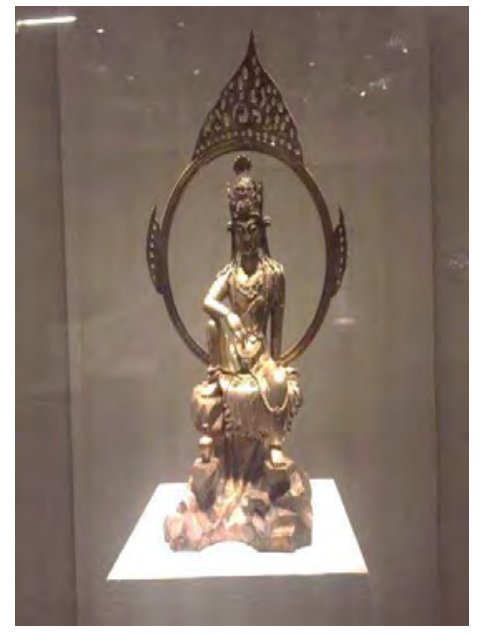

Fig. 8. Copper Shui Yue Kwan-yin Sculpture (the Five Dynasties).

\section{THE ART OF CALLIGRAPHY AND PAINTING IN THE RED AND GREEN PORCELAIN IN THE JIN DYNASTY}

Calligraphy and painting art have an important position and significance in the history of Chinese art. As a unique art type in China, calligraphy has distinct national characteristics and profound traditions. Chinese painting also stands in the world of painting art with its diverse forms and rich content. The art of calligraphy and painting in Jin Dynasty inherited the essence of the Tang and Song Dynasties, was once flourished a while. Along with the development of the art of painting and calligraphy, this art, which originally belonged to the literati, also had a major impact on the masses. In fact, in the Northern Song Dynasty, Cizhou Kiln began to use the art of painting and calligraphy to decorate the ceramics. It can be said that the white and black flower porcelain was produced under such an aesthetic style, but the white and black flowers of this period were good at row flower and tick flower and the brush painting has not become mainstream. To the Jin Dynasty, especially in the middle and late period of Jin Dynasty, the combination of ceramics and painting and calligraphy art became more and more close. There were a large number of brush calligraphy and painting ceramic utensils on the market, and some works even showed the style of the Northern Song Dynasty court painting. As a precious variety of Cizhou kiln, the red and green porcelain is especially expressed this fashion of the times vividly.

\section{A. The Art of Calligraphy in the Red and Green Porcelain in the Jin Dynasty}

Calligraphy is a text art. As early as the Shang and Zhou Dynasties, Chinese calligraphy already had three basic elements: pen, knot and composition. The calligraphy of Han Dynasty already has the distinction of Li, Zhuan and Cursive calligraphy. During the Wei, Jin and Southern and Northern Dynasties, various chirographies have appeared. Since the Sui and Tang Dynasties, calligraphy has prospered and famous people have come forth. To the Song Dynasty, the growth of the literati's class further promoted the development of calligraphy, and its artistry was also more emphasized.
Although Jin is a minority political power, the Jin rulers worshiped the Han culture, and there are many collections of calligraphy and painting in the court ${ }^{3}$. On the basis of inheriting the fine traditions of Tang and Song Dynasties, Jin Dynasty's calligraphy has created a new artistic style. The calligraphy art of Jin Dynasty is very strong and has a rough and honest temperament. This style is reflected in the calligraphy works of famous calligraphers such like Wang Tingjun, Dang Huaiying, Zhao Bingwen and others.

Calligraphy in ceramic art is different from creation on Xuan paper. It must not only follow the writing characteristics of the brush, but also take into account the characteristics of the ceramic itself. The calligraphy on the red and green porcelains in Jin Dynasty is mostly glazed. If the mastery is not good, the glaze is easy to flow. However, the intelligent Cizhou kiln craftsman creates a red, green and colorful ceramic calligraphy art with a sense of time and beauty based on the fully known the ceramic performance and according to the features of the shape and calligraphy art.

In 1961, a white glazed red and green porcelain bowl was unearthed from the Houma Jin Dynasty Tomb in Shanxi Province. The bowl is $5.5 \mathrm{~cm}$ high and $17.8 \mathrm{~cm}$ in diameter. There is a red-colored cursive scripts "Qing" in the bowlshaped diamond-shaped opening. Although there is only one word, but the font is dignified, the brush is clear and powerful, the tone is even and light, which fully shows the deep foundation of calligraphy art in the craftsman.

The Jin Dynasty white glaze red and green porcelain bowl which collected in the Palace Museum has a verse inside it said "Spring night is worth a thousand dollars, flowers have a fragrance and the moon infected shadow under the flower", the font is deep and heavy, calligraphy style is extend, there is a chic and elegant state, this style is quite similar to Wang Tingjun's calligraphy. (See "Fig. 9", "Fig. 10") The poem bowl of red and green porcelain collected in the Wangye Museum, the bowl is $5 \mathrm{~cm}$ high and the diameter is only $9.8 \mathrm{~cm}$. Inside the bowl is written with "Bai Nian Hun Shi Zui, San Wan Wu Qian Chang (If I can live a hundred years, I would like to get drunk for 36,000 times.)", only ten words, the pen-power is vigorous, the atmosphere is majestic, and there is quite a lot of interest in Zhao Bingwen's calligraphy.

The art of calligraphy appearing on Jin Dynasty red and green porcelains is mostly from the hands of the unknown artisans. According to professional standards, such calligraphy art may lack style, rules, artistic concept, etc., but folk artists combined the art of calligraphy they understand with porcelain, which further increases the artistic value of red and green porcelain.

\footnotetext{
3 Wang Dengke. Jin Dynasty's Calligraphy and its Cultural Symptom [J]. Social Science Journal. 2006 (3) 240-243
} 


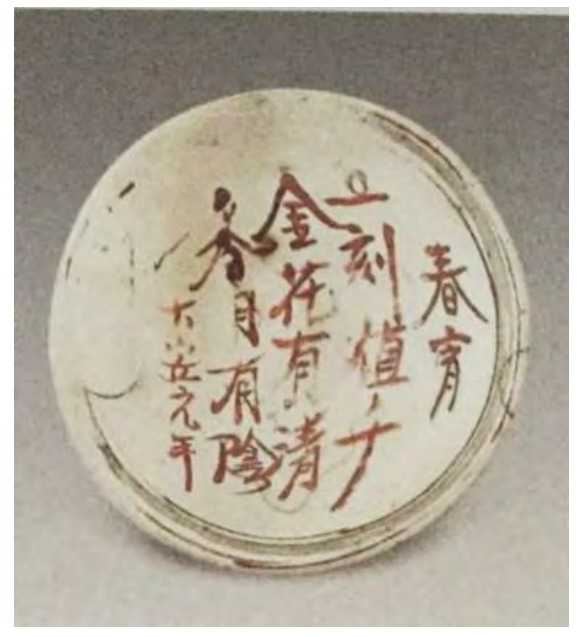

Fig. 9. Poem bowl of red and green porcelain.

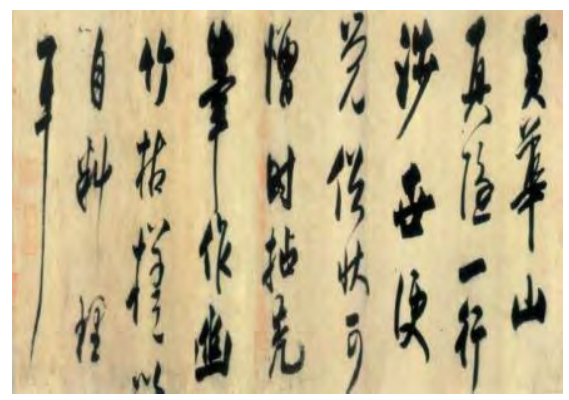

Fig. 10. Calligraphy of Wang Tingjun.

\section{B. The Art of Painting in the Red and Green Porcelain in the Jin Dynasty}

The development of Chinese painting art has gone through a long process, and it became an independent and pure aesthetic object in the Tang and Song Dynasties. The painting themes in the Tang Dynasty mostly focused on religious Buddha images and aristocratic figures, and they pursued the expression of the characters' expressions and charms. ${ }^{4}$ Compared with Tang Dynasty, the paintings of Song Dynasty have a secular and civilian character, except for figure paintings, landscape paintings, flowers and birds painting developed rapidly and achieved great success. The art of painting in the Jin Dynasty was inherited far from the Tang Dynasty, and near from Song and Liao Dynasties, so it also achieved certain achievements. At the beginning of the Jin Dynasty, the literary activities of capitulant from Liao Dynasty and the literati painters entered Jin from Song Dynasty had a great influence on the aesthetic consciousness of the Jin Dynasty nobles. Jin Zhangzong was an emperor who was very accomplished in the art of calligraphy and painting. Under his big support and participation, there have been a group of literati painters represented by Wang Tingyao and Zhao Bingwen, the pursuit of Mi's cloud and mountain and Su's ink

4 Wang Ruohong. The Historical Origins of the Painting Art in the Tang Dynasty [J]. Lantai World. 2012(12)25-26. bamboo became an important part of the court painting activities. ${ }^{5}$

Society is a whole, under the great atmosphere of respecting art at the upper level, the people at the bottom of the society will inevitably be influenced by it, forming a higher awareness of art and culture, those below follow the example of those above, and acting as a custom. The absorption and reference of the painting art by the Jin Dynasty red and green porcelain is mainly reflected in the following two aspects:

First, the reference of painting techniques and composition. The red and green porcelain is a kind of porcelain that is mainly painted and decorated with brush. Compared with traditional Chinese paintings, although the red and green porcelains do not reflect the strict "eighteen strokes" method, their painting techniques have many similarities with traditional Chinese paintings. Judging from the performance techniques of red and green porcelain, the face of the figure is mostly black-colored on the tire mold with the makeup soil, according to the contour of the face, the focus is on the eyebrows, beards and hairpins of the characters. The eyebrows are usually drawn with a thick line as a main body, and then enriched by a number of short lines. The eye uses the general two arcs to outline the upper and lower eyelids, and the eyeballs are expressed in dots. This concise painting technique is very similar to the white paintings since the Tang and Song Dynasties, the former should be formed under the influence of the latter. (See "Fig. 11", "Fig. 12")

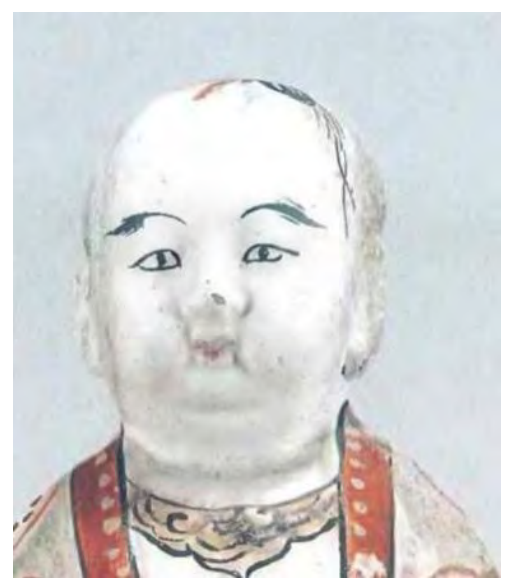

Fig. 11. Figure of red and green porcelain.

\footnotetext{
Hui. Zhang Zongchao's Achievements in Jin Dynasty Paintings [J].New Art 1991(1)45-48.
} 


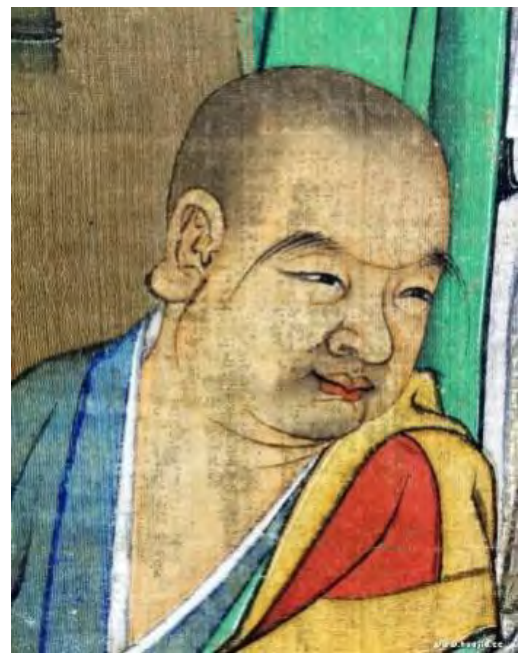

Fig. 12. White drawing of Song Dynasty.

In the composition, the red and green porcelain also has many similarities with the traditional Chinese paintings at that time. The flower and bird patterns and bamboo plum patterns on the red and green porcelain are the same as those of the literati paintings at that time. Most of them adopt the form of folding branch composition to highlight the main image. For example, the common peony pattern occupied the main space with the branch form, with a few leaves; the flower and bird pattern adopts the lateral branching schema, that is, the lateral branching. This composition breaks the single central composition form and adds a sense of life to the picture. (See "Fig. 13", "Fig. 14")

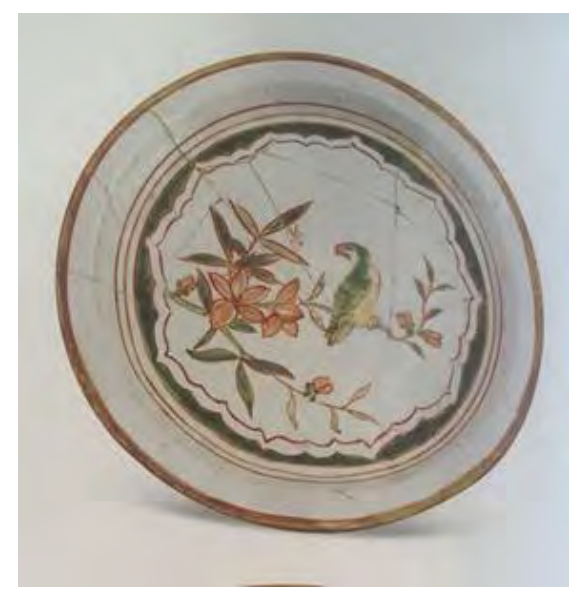

Fig. 13. Flower and bird plate of Red and green porcelain.

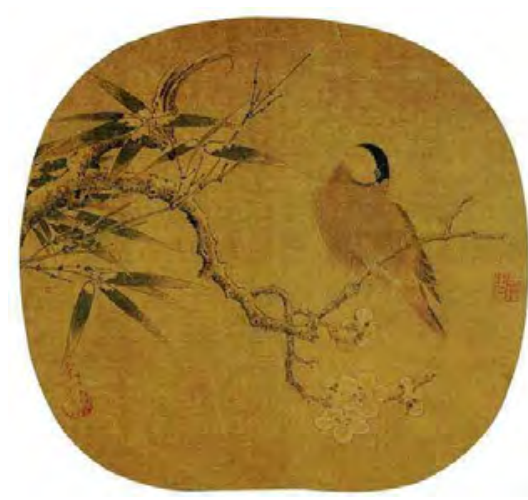

Fig. 14. Bird-and-flower painting of Song Dynasty.

Second, the reference of painting color. There are two main types of color matching in the Jin Dynasty red and green porcelain. The first is a combination of high temperature underglaze black color and upper glaze low temperature red and green color. For example, most of the red and green porcelains are painted in large areas on the semi-finished black and white porcelain, decorated with green and yellow colors. The specific method is to apply red color in the character clothing, for trim or secondary parts filled with green and yellow color. The second is to paint the main theme pattern on the plain white porcelain with red color, and fill the leaves or trim with green and yellow color. For the formation of red and green color, many scholars have explained from the perspective of social culture, but the author believes that the tomb murals of the Jin Dynasty have a direct impact on the formation of red and green porcelain colors. Relevant archaeological data show that the tomb murals of Jin Dynasty are mostly decorated with red, black, white, yellow, green and other colors, of which red is also a color used in large areas. For example, in 1999, the tomb murals of the Jin Dynasty were discovered in the Tunliusong Village of Shanxi. All parts inside the tomb were all painted with color. The method was to use white powder to brush, and then use red, black, yellow and other colors to paint, the northern wall was outlined with black lotus flower, inside it was filled with red and green color; the east wall was outlined with black lotus boy, filled with red, yellow, green and other colors. ${ }^{6}$ This color matching is exactly the same as the color technique of red and green porcelain. This tomb was created in 1135 , a little earlier than the creation of red and green porcelain, so it is very possible that the red and green porcelain was influenced by the tomb murals. Similar to this tomb decoration style, there are Jin Dynasty mural tombs of Liuhe Canal in Ganquan, Shaanxi, Jin Dynasty mural tombs in Nanguan Village of Fanzhi, Shanxi Province, and Jin Dynasty Tomb of Dongwan Village in Jiachuan Township, Qingshui County, Gansu Province.

\section{THE LITERARY EXPRESSION OF RED AND GREEN PORCELAIN IN THE JIN DYNASTY}

Before the founding of the Jin Dynasty, the Jurchen were in the social form of tribal alliance, and they were quite

Shanxi Institute of Archaeology. Jin Dynasty mural tomb in Tunliusong Village, Shanxi Province [J]. Cultural Relics 2008 (8) 55-62. 
backward in culture. Before the war of the Liao Dynasty, they did not have their own words. In the early days of the founding of Jin Dynasty, the Jurchen rulers began to absorb the Han culture, and through a variety of means such as recruiting rebellion, detaining the ambassador, and put them in an important position, they gathered a large number of Liao and Song Confucian talents and changed their backwardness.

Because the Jin Dynasty rulers respect Confucianism and attach importance to Chinese culture, the literati have a very high social status in the Jin Dynasty. Therefore, reading books and reciting the words, taking the imperial examinations, entering the court as an official, has become the most desirable way out for the common people. This kind of social situation is also reflected in the red and green porcelain. For example, a boy statue of red and green porcelain collected by the Wangye Museum in Shenzhen is $12.6 \mathrm{~cm}$ high and $12.8 \mathrm{~cm}$ wide, the boy has round head and big ears, black painted eyebrows and red dot for lip, eyes almost closed, leaning on a square pillow, right arm flexion, left arm hanging, left hand holding an open book on the left knee, the book is also painted with black color. (See "Fig. 15") In addition, a red and green figure statue unearthed in Qufu, Shandong Province in 1954, it is $30.5 \mathrm{~cm}$ high, the face is full and the facial features are in proportion, he has handlebar mustache, his brows slightly frown, seems to think something, and he hold the book with both of his hands up to his chest, with a serious and solemn image of an officer.

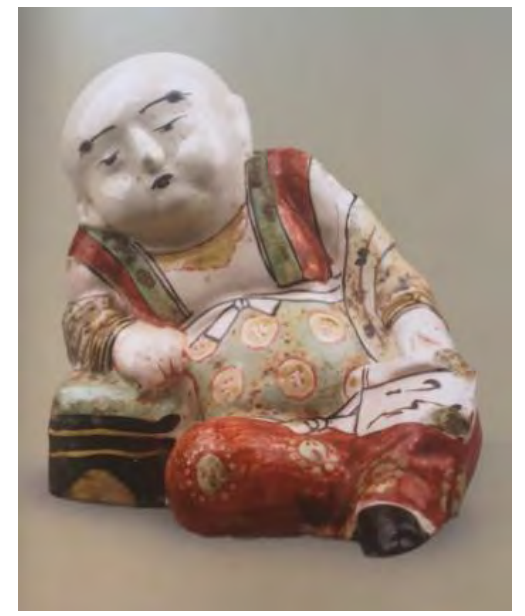

Fig. 15. Reading boy of Red and green porcelain.

Although the Jin Dynasty literature was largely influenced by the Song Dynasty literature, it was rooted in the soil of the northern culture, thus forming a unique literary trait that is different from Tang and Song. The Jin Dynasty literature has developed a lot in the period of Shizong and Zhangzong Emperor. This period is a golden age in the history of Jin Dynasty literature, and a large number of literati represented by Yuan Haowen emerged. The prosperity of literature has promoted the improvement of the national knowledge level of the entire Jin Dynasty, which is particularly evident in the red and green porcelain.

The poems on the red and green porcelain are mainly written on bowls and plates. Because of the small size of such utensils, the most common are five-character poems and four- character sentences. Most of these poems quote the poems of famous Tang and Song poets and popular slang, proverbs, and auspicious words. Shenzhen Wangye Museum collects a red and green color poem bowl, inside the bowl is written in red color "Bai Nian Hun Shi Zui, San Wan Liu Qian Chang", this verse is from Su Shi's "Man Ting Fang", the original sentence is "Bai Nian Li Hun Jiao Shi Zui, San Wan Liu Qian Chang", which means that life is short, even if we get drunk every day, it is only 36,000 times. Su Shi's officialdom was lost in his later years; this verse is also a deep sigh of his longing which was never requited. The porcelain craftsmen wrote these fivecharacter poems on the red and green bowl, on one hand, it promoted the products and increased their desire to purchase; on the other hand, it also expressed their feelings for a short life. (See "Fig. 16") There is a poem bowl in the Cizhou Kiln Museum in Ci County, Hebei Province, the inside of the bowl is decorated with the words "You Hua Fang Yin Jiu, Wu Yue $\mathrm{Bu}$ Deng Lou", this verse not only depicts the ancients' appreciation and elegance of the moon and wine, it also reflects their love of life and yearning for beauty. (See "Fig. 17") A red and green porcelain bowl collected by the Cizhou Kiln Art Museum in Fengfeng Mining Area of Hebei Province, the diamond-shaped opening of the bowl heart has a verse of Tang poem: "Ju Shui Yue Zai Shou, Nong Hua Xiang Man Yi", the verse is from Tang Dynasty Yu Lianshi's "Chun Shan Yue Ye". Yu Liangshi is not a famous poet in Tang Dynasty, but this short poem verse expresses the elegant and romantic feelings in the depths of the ancients with a short ten words. A red and green porcelain poem bowl collected in a private person in Henan Province, the heart of the bowl has a greencolored red side composed of sunflower-shaped opening, with writing inside: "Yi Ye Luo Hua Yu, Man Cheng Liu Shui Xiang". This verse is from the poem of the Zen Master Zhi Jian of the Northern Song Dynasty. The whole poem is "Zun Shi You Mi Yu, Jia Ye Bu Fu Cang, Yi Ye Luo Hua Yu, Man Cheng Liu Shui Xiang". This poem contains profound religious philosophies, the general idea is that nature is equal to human beings, just like a night of rain that makes the flowers fall down, dyed the city full of fragment water, but the feelings of people in this city are different, some people can smell but someone cannot.

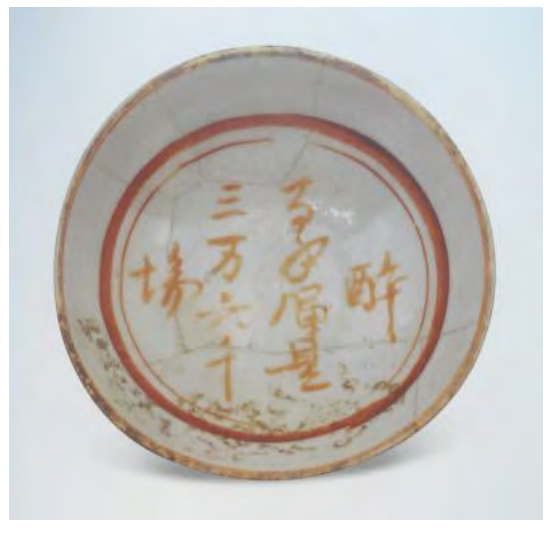

Fig. 16. "Bai Nian Hun Shi Zui" bowl of Red and green porcelain. 


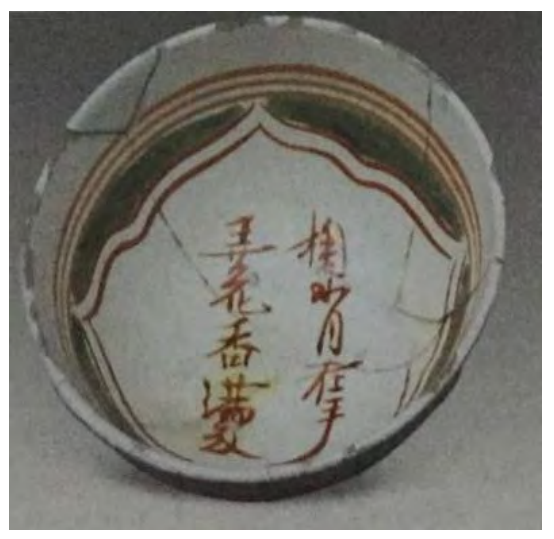

Proceedings of the Chinese Red and Green Porcelain Symposium [C] Beijing: Cultural Relics Publishing Company 2011: 160. (in Chinese)

[6] Wang Dengke. "The Calligraphy of Jin Dynasty and Its Cultural symptoms"[J].Social Sciences Journal.2006(3)240-243. (in Chinese)

[7] Wang Ruohong. "The Historical Origin of the Painting Art in Tang Dynasty[J].Lan tai World.2012(12)25-26. (in Chinese)

[8] Yu Hui. "Zhang Zongchao's Achievements in Jin Dynasty's Painting”[J].New Art.1991(1)45-48. (in Chinese)

[9] Shanxi Provincial Institute of Archaeology. "Tomb of Jin Dynasty Mural in Tunliusong Village, Shanxi Province [J]. Cultural Relics 2008 (8) 55-62. (in Chinese)

[10] Wang Xiaochun. "Analysis of the Artistic Characteristics of Red and green Porcelain sculptures in Jin Dynasty" [A]. Edited by Shenzhen Museum. Red and Green Porcelain Symposium [C] Cultural Relics Publishing Company. 2011:221-235. (in Chinese)

Fig. 17. "Ju Shui Yue" bowl.

In addition to the above-mentioned typical examples, there are also philosophical poems such as "Jiu Zhong Ceng De Dao" (monk realizes the truth from the wine), "Yue Ri Wu Bing Shan" (the moon is like a non-handle fan), "Feng Yao Qing Mai Lang" (rippling green wheat in the wind), "Xing Hua Han Wei Fa" (apricot Apricot flower is not blooming due to cold day), and so on, here we do not explain one by one. The emergence of these poems fully demonstrates the prosperity of the development of literature and art at that time and its penetration into the people.

\section{CONCLUSION}

As a precious variety of porcelain created by Cizhou kiln, the technical, artistic and cultural characteristics of Jin Dynasty red and green porcelain are very prominent, which is closely related to the development of social economy and culture in the middle and late period of Jin Dynasty. The outstanding cultural and artistic achievements of Jin Dynasty have nourished the secular life of social beings. The art of red and green porcelain, which is closely related to the people's clothing, food, housing and transportation, is influenced by its style is the most natural thing. The red and green porcelain blended the sculptures, paintings and literary arts at that time, which not only vividly reflected the social and cultural features of the time, but also created its remarkable artistic achievements.

\section{REFERENCES}

[1] Yang Xiaozhong, Liang Huiying, Wang Yu. "The Form and Spirit of Chinese Traditional Sculpture"[J]2011(5). (in Chinese)

[2] Wang Xing. "Poetry in Red and Green Porcelain" [A]. Edited by Zhang Liping,Zhang Meifang. Inheritance and Innovation of Cizhou Kiln Culture. Beijing: Cultural Relics Publishing Company 2017:147-154. (in Chinese)

[3] Sun Facheng. "Porcelain pillow in Song Dynasty" [M] Xiamen: Xiamen University Publishing, 2015: 73-88. (in Chinese)

[4] Ma Xiaoqing. "Analysis of the decoration technique of red and green color in Cizhou kiln" [A]. Edited by Shenzhen Museum. Red and Green Porcelain Symposium [C] Cultural Relics Publishing Company 2011:215. (in Chinese)

[5] Huang Yangxing. "Solemn vivacity — red and green sculptures and the Buddhist beliefs of the Jin Dynasty" [A] Edited by Shenzhen Museum. 